\title{
Recovery of oil and free fatty acids from spent bleaching earth using sub-critical water technology supported with kinetic and thermodynamic study
}

\author{
Rehab Abdel Fattah ${ }^{1}$, N. A. Mostafa ${ }^{2}$, Mohamed S. Mahmoud ${ }^{1}$, Wael Abdelmoez ${ }^{{ }^{*}}$ \\ ${ }^{1}$ Chemical Engineering Ddepartment, Minia University, Minia, Egypt \\ ${ }^{2}$ Faculty of Aapplied Mmedical Sscience, Taif University, Taif, KSA \\ Email: *drengwael2003@yahoo.com
}

Received 5 December 2013; revised 18 January 2014; accepted 26 February 2014

Copyright (c) 2014 Rehab Abdel Fattah et al. This is an open access article distributed under the Creative Commons Attribution License, which permits unrestricted use, distribution, and reproduction in any medium, provided the original work is properly cited. In accordance of the Creative Commons Attribution License all Copyrights (c) 2014 are reserved for SCIRP and the owner of the intellectual property Rehab Abdel Fattah et al. All Copyright (C) 2014 are guarded by law and by SCIRP as a guardian.

\section{ABSTRACT}

This work represents the extraction of oil with high free fatty acid content from spent bleaching earth using sub-critical water technology as a greener production pathway. The extraction efficiencies under different conditions were investigated. The studied parameters include temperatures in the range of 180 to $270^{\circ} \mathrm{C}$, the feed to solventfeed-to-solvent (in this case water) ratio (1:1, 1:2, 1:3, 1:4 and 1:5) and extraction times in the range of 5 - 60 minutes. The results showed that the optimum temperature, feed to solventfeed-tosolvent ratio, and extraction time were $270^{\circ} \mathrm{C}, 1: 3$, and 20 minutes, respectively. In another experiment, the extracted free fatty acids were converted into mono-, di-, and triglycerides through esterification with glycerol to increase the value added of the extracted products. The kinetics of the extraction process was found to be corresponding to an irreversible consecutive unimolecular-type first order reaction, consisting of the extraction step followed by the decomposition reaction step. Both reaction rates of extraction and decomposition were estimated using the reaction rate equations utilizing the nonlinear regression method. The apparent activation energy was calculated to be $46.1 \mathrm{~kJ} \cdot \mathrm{mol}^{-1}$. This result indicates a diffusion controlled reaction. For more exploration and deep understanding of the extraction mechanism, other thermodynamic parameters were also calculated and analyzed including, $\Delta H \#, \Delta S \#$, and $\Delta \mathbf{G} \#$ of the extraction step.

\section{KEYWORDS}

Spent Bleaching Earth; Sub-Critical Water

${ }^{*}$ Corresponding author.
Technology; Kinetics of Extraction; Thermodynamic Parameters

\section{INTRODUCTION}

Bleaching earth, often called fuller's earth, is a type of clay that is a mineral-rich substance. Such clay is processed and used for adsorbing, bleaching, and filtering processes. After industrial use, the clay must again undergo processing in which it is recycled for reuse or rendered safe for disposal.

Bleaching earths are natural or acid-activated bentonite clays that are extensively used for refining edible oils; they adsorb color and other impurities and improve the oil flavor and stability. Spent bleaching earth (SBE) usually contains between $17 \%$ and $28 \%$ by weight (wt) of oil with high content of free fatty acids, which is not removed during the final filter pressing process. Accordingly, it should be treated carefully prior to its disposal. Fire hazard due to spontaneous auto-ignition is the main concern with handling SBE from the bleaching of unsaturated vegetable oils [1], and it is therefore classified as hazardous waste (European Waste Catalogue, 0706 10*). Untreated SBE cannot be landfilled due to its high organic content, which exceeds the $6 \%$ limit of the waste acceptance criteria for hazardous waste landfills under the EU Landfill Directive [2]. Incineration of SBE remains the main disposal method in Europe. In 2007, about the hazardous waste management unit of the city of Alexandria, Egypt announced that the annual generation of SBE in Egypt was around 10,000 tonnes/year, and it has been identified as one of the main problematic hazardous wastes generated by the food industry. The Nassereya Hazardous Waste Treatment Centre (NHWTC) 
near Alexandria is the only treatment and disposal facility for hazardous wastes in Egypt [3]. It is operated to meet the requirements of the EU Landfill Directive and therefore cannot accept SBE for disposal.

Due to the increasingly high cost of disposal, it is desirable to use, or reuse, the material instead of landfilling it. Several treatment options have been proposed for SBE. Oil extraction has been used to treat SBE, so it can be safely landfilled using organic solvents [4,5]. Hexane extraction of SBE is economically feasible for expensive and relatively stable oils only. The extracted oil is generally of low quality, having high free fatty acids and peroxide value, and would not be suitable for food application, but can be used as a cheap feedstock for conversion to biodiesel [6-8]. Other options include using SBE as an alternative fuel in cement kilns or as a feedstock for the production of clay bricks. However, due to economic, ecological and/or logistical issues, these methods have not been widely used by the industry. Lately, subcritical water technology has attracted many researchers for its versatile applications in the field of environment as a green alternative process to solvent extraction. On heating within the critical point of water (temperature < $374^{\circ} \mathrm{C}$, pressure $22.1<\mathrm{MPa}$ ) under enough pressure to maintain the liquid state, water (subcritical water in this state) was reported to have distinctive properties, such as a low dielectric constant and a high ion product. Many extractable components from different biomasses could be easily extracted under these conditions. A historical as well as technological review for the different applications of the subcritical water technology was provided elsewhere $[9,10]$. It was reported that relatively large amounts of oil, organic acids, and amino acids could be extracted from oil-containing biomasses, such as fish, squid entrails and meat wastes by subcritical water [11]. In addition, amino acids and organic acids were extracted using subcritical water from protein [12-15]. Both cottonseed and jojoba oils were extracted using subcritical water $[16,17]$.

In the present work, the extraction of oil from bleaching earth using sub-critical water technology was investigated as a new emerging technique for oil extraction and it is strongly nominated to be an alternative cleaner extraction method whereby water instead of organic solvents being used as the extraction medium. After finding out the optimum extraction conditions, the extracted oil, which mainly contains free fatty acids, could be converted to fatty acid esters, mono-, di-, and triglycerides through an acid-catalyzed esterification reaction with glycerol. Such fatty acid esters could be used as raw materials for emulsifiers or as oiling agents for foods, spin finish and textiles; lubricants for plastics and for mechanical processing; paint and ink additives; personal care emollients; surfactants and base materials for per- fumes [18].

\section{MATERIALS AND METHODS}

\subsection{Materials}

The bleaching earth used in this work was supplied by EL MANAR plant, El-Nobareyya city, El-Beheyra governorate (province), Egypt. Distilled water prepared in the Chemical Engineering department, Minia University, was used as an extracting solvent in subcritical water extraction. Ethanol was used (as solvent) for titration to determine free fatty acids, methanol was used as solvent for Thin Layer Chromatography (TLC) analysis to determine mono-, di-, and triglycerides, chloroform was used as solvent for TLC analysis to prove the existance of the mono-, di-, and triglycerides; and $\mathrm{NaOH}$ was used as a catalyst and in titration of the free fatty acid. The TLC paper was the product of TLC, Kieselgel $60 \mathrm{f} 254$ precoated plates, E. Merck, Darmstadt, Germany.

\subsection{Methods}

\subsubsection{Measuring of Oil Content in the Bleaching Earth}

Before starting the experiments, the amount of oil contained in the SBE was measured. SBE as delivered from EL MANAR plant was extracted by petroleum ether. Five grams of SBE were contained in a 500-ml container with a sealed cape and $200 \mathrm{ml}$ of petroleum ether were added to the SBE. The container was then tightly closed and mixed using a magnetic stirrer over a hotplate adjusted at $45^{\circ} \mathrm{C}$. The SBE was separated from the extraction mixture by filtration. Then, the extracted oil was recovered by evaporating the solvent.

\subsubsection{Subcritical Water Extraction (SCE)}

The SCE was carried out in a laboratory-built apparatus. It was carried out in stainless steel pipes SUS 316, i.d. $1.68 \mathrm{~cm} \times 15 \mathrm{~cm}$ (with a reactor volume of $34 \mathrm{~cm}^{3}$ ) with Swadgelock caps. The bleaching earth was charged into the reactor tube, then the distilled water was added as an extraction solvent. The reactor was sealed and immersed in a heating bath (Thomas Kagaku Co. Ltd.). It is important to note here as a safety comment that the sealed tube should not be overfilled to prevent hydraulic pressure of the expanding liquid from fracturing the tube vessel. The extraction was carried out in the range of $180^{\circ} \mathrm{C}-280^{\circ} \mathrm{C}$, and the pressure inside the reactor was estimated from the steam table for the subcritical conditions (saturated steam). After the desired reaction time, the reactor was immediately cooled down by immersing it into a coldwater bath. The extraction product was separated into three phases: the oil phase, the aqueous phase (including oil and water), and the solid phase. The three phases were separated through simple centrifugation and vacu- 
um filtration processes. To recover any traces of oil from the aqueous phase, we added petroleum ether to extract any oil that could be emulsified into the water phase. Then, the petroleum ether was evaporated by heating it in a furnace at $80^{\circ} \mathrm{C}$. The extracted oil was then weighed and the data was recorded.

\subsubsection{Esterification of Fatty Acid with Glycerol}

Esterification reactions were carried out according to the methods and optimum conditions described elsewhere (Ashraf, 2013) in a laboratory-built apparatus. A laboratory conical flask of $250 \mathrm{ml}$ with $30 \mathrm{ml}$ working volume was used for the reaction. The temperature of the reactor was controlled using a hot plate controlled with an internal thermostat. All the reactants (fatty acid, glycerol and catalyst) were weighed in the desired amount and charged into the reactor. The temperature was then increased through adjusting the thermostat. The magnetic stirrer was allowed to operate after 2 - 3 minutes (to allow for heating up of the mixture). After the desired reaction time elapsed, the heater was closed. The reactor was then cooled by immersing it into a water bath. When the reaction mixture reached ambient temperature, samples were taken for analysis.

\subsubsection{Analytical Methods}

Determination of the acid value for free acid determination

Five grams of the sample at time intervals were dissolved in ethanol and phenolphthalein indicator was used to determine the $\mathrm{pH}$ change during the esterification reaction. The titration was carried out against an aqueous solution of $0.1 \mathrm{~N} \mathrm{KOH}$. Acid value (A.V) was determined according to the equation given below:

$$
A . V=\frac{56.1 \cdot N \cdot V}{M} \mathrm{mg}
$$

where:

$N$ : normality of $\mathrm{KOH}$ solution

$V$ : the volume of solution employed for titration, $\mathrm{ml}$

$M$ : weight of fatty acids sample, $g$

\section{Determination of the fatty acids conversion}

Titration method was selected for the determination of the fatty acids conversion during the esterification reaction because it is a simple and efficient analytical method that could be performed without the need for highly specialized equipment. The fatty acids conversion was calculated considering that the fatty acids are composed mainly of oleic acid. Five grams of the esterification reaction mixture was dissolved in ethanol and phenolphthalein indicator was used. The titration was carried out against an aqueous solution of $0.1 \mathrm{~N} \mathrm{KOH}$. Free fatty acid (F.F.F. \%) was determined using the following equation:

$$
\text { F.F.F. conversion } \%=\frac{A_{i}-A_{t}}{A_{i}} \cdot 100
$$

where $A_{i}$ is the initial acidity of the mixture and $A_{t}$ acidity at any time, $\mathrm{t}$.

\section{Thin-layer chromatography for the produced gly-} cosides

Thin layer chromatography (TLC) was used to identify the types of glycerides produced during the esterification reaction (i.e mono-, di- or triglycerides). TLC experiments were carried out by dissolving one drop of the esterification products into a $0.5-\mathrm{ml}$ mixture of chloroform and methanol (9:1). A drop from the final mixture was then applied over the TLC paper immersed into a $100-\mathrm{ml}$ beaker containing $10 \mathrm{ml}$ of a mixture of chloroform and methanol (9:1) which allows a contact between the edges of the TLC paper with the solvent mixture. The TLC paper was allowed to stand until the solvent reached a level which must be just below the end line. The TLC paper was then dried and the bands of the different glycerides produced were detected under the UV lamp.

\section{THEORETICAL PART}

\subsection{Kinetic Studies}

The oil extraction process could be viewed as an irreversible consecutive unimolecular-type first order, in which the oil is firstly extracted from the bleaching earth by diffusion following a first order-like mechanism. Then the extracted oil, due to extending the extraction time under the high temperature and pressure, is subjected to a decomposition reaction following a first order mechanism. Accordingly, the oil extraction process could be simplified into the following reaction scheme,

$$
\mathrm{A} \rightarrow \mathrm{R} \rightarrow \mathrm{S}
$$

Where $\mathrm{A}, \mathrm{R}$ and $\mathrm{S}$, represents the total oil in the bleaching earth, extracted oil, and the decomposition product, respectively, and $\mathrm{k}_{1}$ and $\mathrm{k}_{2}$ represent the specific reaction rate constants for the extraction and decomposition steps, respectively.

The rate equations for the three components are:

$$
\begin{gathered}
d C_{a} / d t=-k_{1} C_{a} \\
d C_{r} / d t=k_{1} C_{a}-k_{2} C_{r} \\
d C_{s} / d t=k_{2} C_{r}
\end{gathered}
$$

where $C_{a}, C_{r}, C_{s}$, represent the concentration of the total oil in the bleaching earth, the concentration of extracted oil, and the concentration of decomposition product, respectively.

Integration of the rate equations results in:

$$
-\ln \left(C_{a} / C_{a o}\right)=k t \text { or } C_{a}=C_{a o} e^{-k 1 t}
$$

where $C_{a o}$ represents the initial concentration of the oil in 
the bleaching earth.

To find the variation in concentration of $\mathrm{R}$, substitute the concentration of A from Equation (1) into the differential equation governing the rate of change of concentration of the extracted oil, R:

$$
d C_{r} / d t+k_{2} C_{r}=k_{1} C_{a 0} e^{-k 1 t}
$$

By integration of Equation (5), the final variation in concentration of the extracted oil, $\mathrm{R}$, is:

$$
C_{r}=C_{a 0} k_{1}\left[e^{-k 1 t} /\left(k_{2}-k_{1}\right)+\left(e^{-k 2 t} /\left(k_{1}-k_{2}\right)\right)\right]
$$

Equation (6) has been used to elucidate the concentration time course of oil extraction from bleaching earth.

\subsection{Thermodynamic Study}

The oil extraction process was also analyzed thermodynamically. The Arrhenius equation was used for describing the temperature dependence of the reaction rate. The Arrhenius equation is founded on empirical observation and common sense, that is, the chemical perception which suggests that the higher the temperature the faster a given chemical reaction will proceed (Equation (7)).

$$
K=A \exp [-E / R T]
$$

where $A$ is the pre-exponential factor (sometimes called frequency factor, or prefactor), $E$ is the activation energy, $T$ is the absolute temperature, and $R$ is the gas constant $(8.31451 \mathrm{~J} /(\mathrm{mol} \cdot \mathrm{K}))$.

Integration of both sides of Equation (7) yields:

$$
L n k=-E a / R T+\ln A
$$

By plotting $L n k$ vs. $1 / T$, a linear relationship is obtained and one can determine $E a$ from the slope (-Ea/R) and $\mathrm{A}$ from the $\mathrm{y}$-intercept. This equation assumes that $E a$ and $A$ are constants or nearly constant with respect to temperature.

The activation thermodynamic parameters were calculated from the transition-state theory using the Eyring equation. Eyring (1935) formulated his equation, which represents a theoretical construct, based on transitionstate theory. The Eyring equation in its thermodynamic version becomes:

$$
\begin{gathered}
k=(k b T / h) e^{-\Delta G \# / R T} \\
k=(k b T / h) e^{\Delta S \# / R} e^{-\Delta H \# / R T}
\end{gathered}
$$

where $\mathrm{k}$ is the rate constant, $\Delta \mathrm{G} \#$ is the standard Gibbs free energy of activation, $\Delta \mathrm{H} \#$ is the standard enthalpy of activation, $\Delta \mathrm{S} \#$ is the standard entropy of activation, $\mathrm{kb}$ is the Boltzmann constant $\left(1.380658 \times 10^{-23} \mathrm{~J} . \mathrm{K}^{-1}\right)$, $\mathrm{h}$ is
Planck's constant $\left(6.6260755 \times 10^{-34} \mathrm{~J} . \mathrm{s}\right), \mathrm{R}$ is the gas constant, and $\mathrm{T}$ is the absolute temperature in Kelvin.

On taking a logarithm for both sides of Equation (10), one obtains:

$$
\ln (k / T)=\left[\ln (k b / h)+\left(\Delta S^{\#} / R\right)\right]-\Delta H^{\#} / R T
$$

By plotting $L n(k / T)$ vs. $1 / T$, a linear relationship is obtained and one can determine $\Delta H$ from the slope which is equal to the value $\left(\Delta H^{\#} / R\right)$ and $\Delta S^{\#}$ is determined from the $y$-intercept $\left[\ln (\mathrm{kb} / \mathrm{h})+\left(\Delta S^{\#} / R\right)\right]$.

The Gibbs free energy of activation can be determined by:

$$
\Delta G^{\#}=\Delta H^{\#}-T \Delta S^{\#}
$$

\section{RESULTS AND DISCUSSION}

The first step was to estimate the amount of oil contained in the bleaching earth used in the study. The SBE was easily measured according to the method described and found to be $25 \%$ by weight based on the dry weight of the bleaching earth. This percentage was taken as the maximum oil content of the used earth. The yield of oil extraction using subcritical water was based on this oil content and was calculated as Equation (13).

To find out the optimum extraction conditions, the extraction process was carried out under different conditions. The tested parameters were the temperature, time of extraction and the feed-to-solvent ratio.

To study the effect of temperature on the extraction process, the subcritical water extraction process was carried out by changing the extraction temperature while keeping other parameters constant. The temperatures tested were in the range of $180^{\circ} \mathrm{C}-280^{\circ} \mathrm{C}$. Figure 1 shows (a) the effect of the extraction temperature on the overall yield of extracted oil and (b) the effect of the temperature on the total solid residue. The extraction proceeded for $30 \mathrm{~min}$. of extraction time using $5 \mathrm{~g}$ of bleaching earth and $15 \mathrm{gm}$ of distilled water as a solvent (feed-to-solvent ratio of 1:3). The results showed that the yield of extraction increased with increasing temperature to a certain level, and then it decreased. The maximum yield was $66.32 \%$ at $270^{\circ} \mathrm{C}$ (which represents 0.829 grams of oil from a maximum containing value of 1.25 grams present originally in the SBE). However, the measurements of solid residual during the extraction process showed a linear reduction in the solid residual content when increasing the temperature.

The second studied parameter was the optimum extraction time. In this part of the study, the extraction was carried out within a temperature range of $180^{\circ} \mathrm{C}-270^{\circ} \mathrm{C}$,

$$
\text { Yield } \%=\frac{\text { The weight of extracted oil }}{\text { The weight of bleaching earth used in the experiment } \times 0.25} \times 100
$$




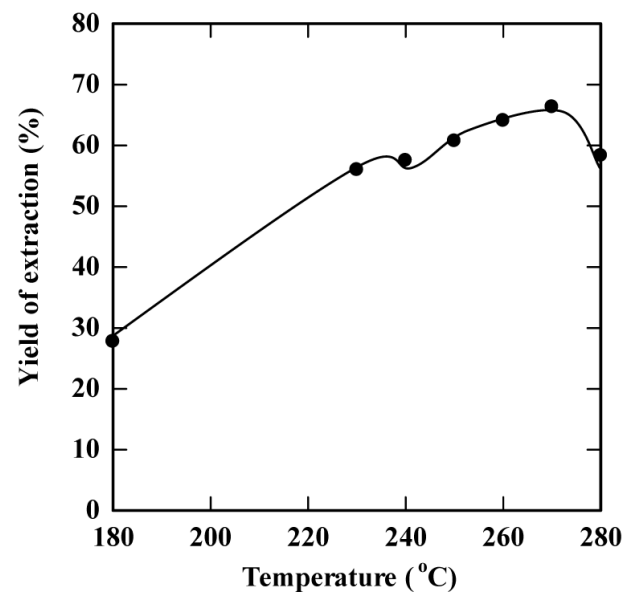

(a)

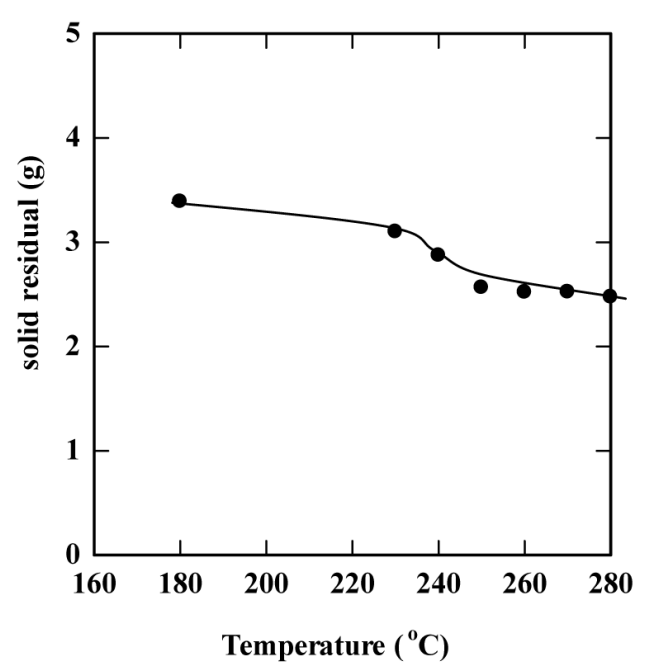

(b)

Figure 1. Effect of the temperature on the yield of extraction (a) and the solid residual (b) The experiments were carried out using feed to solvent of 1:3 and for 30 min extraction time.

feed-to-solvent ratio 1:3. The extraction time was in the range of 5 to 50 minutes while keeping other parameters constant. Based on these conditions, the experiments were accomplished and the optimum extraction time and solid residue were determined. Figures 2-6 show the time course of oil extraction at different temperatures in the tested

The maximum recorded yields were found to be $49.12 \%, 56 \%, 64.4 \%, 64.08 \%$ and $98.4 \%$ for extraction temperatures of $180^{\circ} \mathrm{C}, 230^{\circ} \mathrm{C}, 250^{\circ} \mathrm{C}, 260^{\circ} \mathrm{C}$ and $270^{\circ} \mathrm{C}$, respectively. It was observed that the yield of oil extracted increased up to a maximum value, and then reduced by increasing the extraction time. Such reduction is due to the decomposition of some extracted oil into degradable products such as organic acids that settled and separated from the floated oil phase into the water phase.

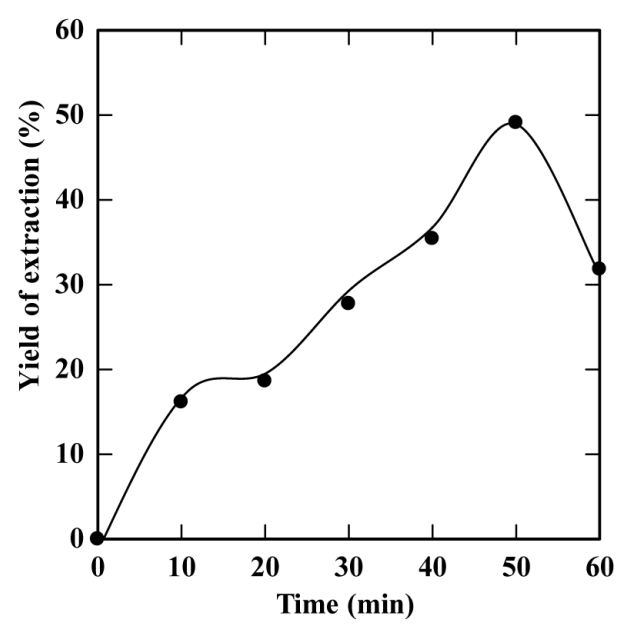

(a)

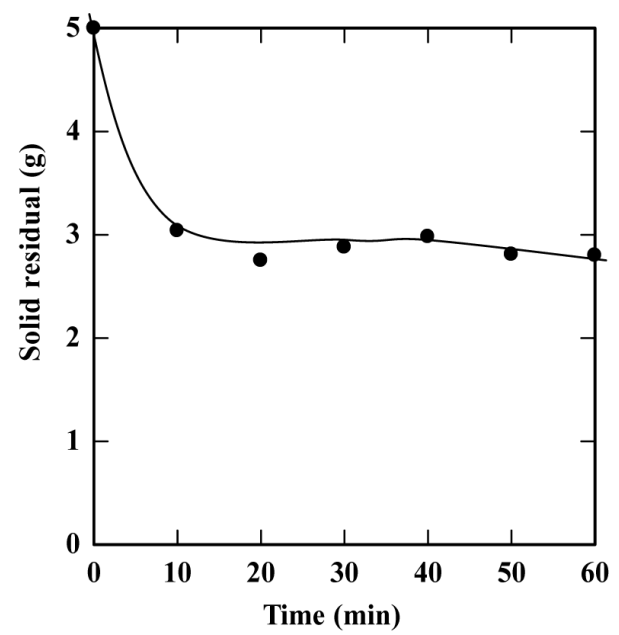

(b)

Figure 2. Effect of extraction time on the yield of extraction (a) and solid residual (b) at $180^{\circ} \mathrm{C}$ The experiments were carried out using feed to solvent ratio of $1: 3$ and extraction time of 30 $\min$.

The concluded results of this part are that the optimum extraction temperature and time are $270^{\circ} \mathrm{C}$ and $20 \mathrm{mi}-$ nutes, respectively.

Now let us discuss the feed-to-solvent ratio to get its optimum value. The tested feed-to-solvent ratios were 1:1, 1:2, 1:3, 1:4 and 1:5. Figure 7 shows the effect of the feed-to-solvent ratio on the yield of extracted oil. Experiments were carried out at $270^{\circ} \mathrm{C}$ for 20 minutes of extraction time. It was clearly found that by increasing the ratio of the feed to the solvent the yield of extraction increased too. The maximum extraction yield was $66.32 \%$ at a feed:solvent ratio of 1:3. It is very important to note that increasing the amount of water above 1:5 could not happen because of the dramatic increase of the pressure inside the reactor which hindered the easy opening of the reactor and led to explosion-like performance during the 


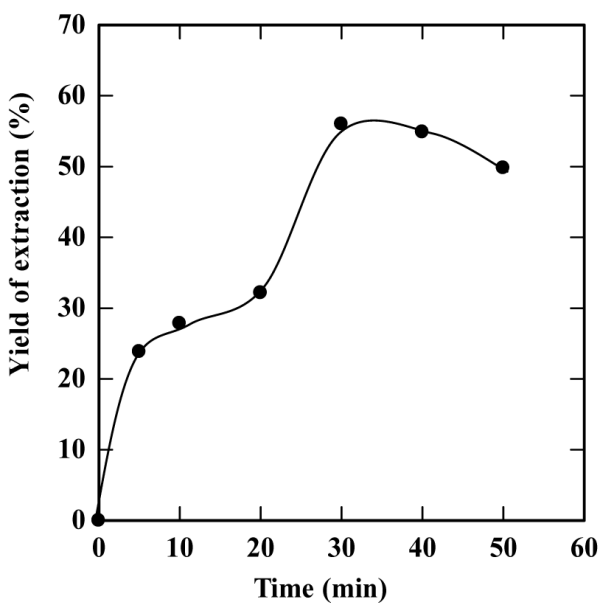

(a)

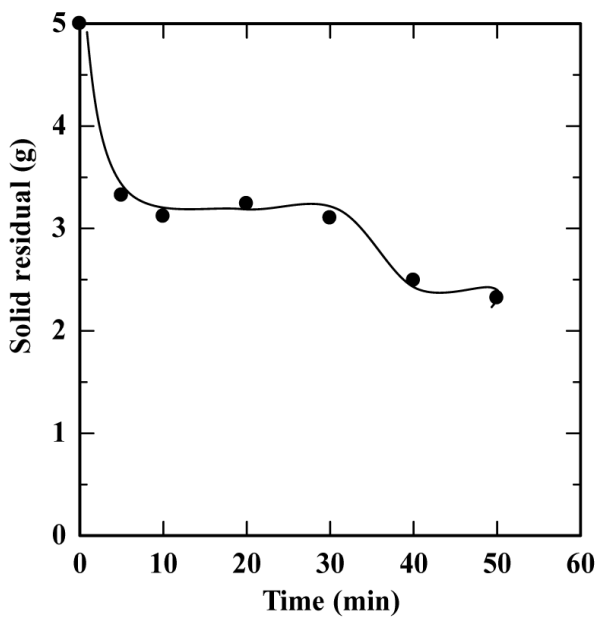

(b)

Figure 3. Effect of extraction time on the yield of extraction (a) and solid residual (b) at $230^{\circ} \mathrm{C}$ The experiments were carried out using feed to solvent ratio of $1: 3$ and extraction time of $30 \mathrm{~min}$.

opening of the reactor to recover the extraction product. The results showed that the maximum yield was $98.4 \%$ from the oil contained originally in the bleaching earth. Accordingly, the optimum conditions of subcritical water extraction of oil from SBE would be as follows:

- Extraction temperature: $270^{\circ} \mathrm{C}$

- Time: 20 min.

- Feed-to-solvent ratio: 1:3

Comparing the obtained results with those obtained for the cottonseed and jojoba oil extraction, some interesting conclusions could be obtained. In the case of cottonseed oil, temperature was the same as that obtained in the present work for the SBE. But in the case of jojoba oil extraction, the optimum temperature needed for extraction was $240^{\circ} \mathrm{C}$, which is lower than that in the case of cottonseed and SBE. This may be explained based on the oil content. The oil content in cottonseed, SBE, and jo-

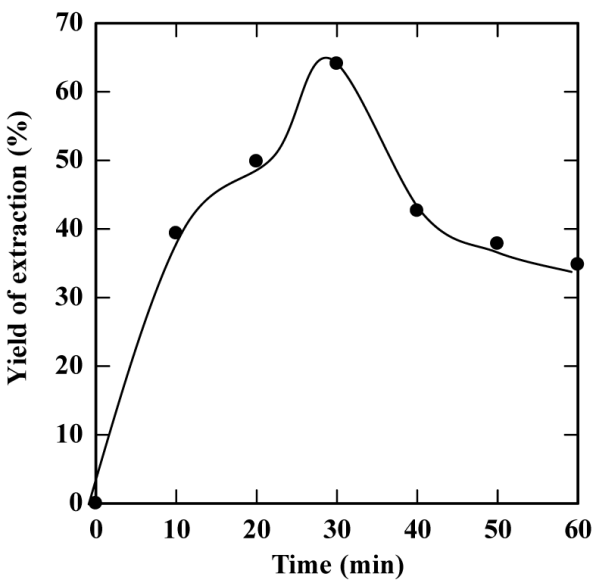

(a)

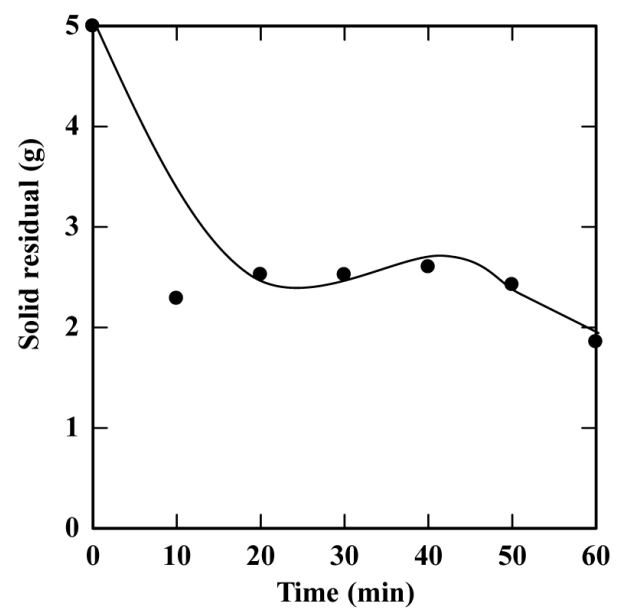

(b)

Figure 4. Effect of extraction time on the yield of extraction (a) and solid residual (b) at $250^{\circ} \mathrm{C}$ The experiments were carried out using feed to solvent ratio of 1:3 and extraction time of $30 \mathrm{~min}$.

joba is $15 \%, 25 \%$ and $48 \%$, respectively. The optimum extraction time was the same in all cases $[14,15]$.

\subsection{Esterification of Free Fatty Acids with Glycerol}

In this part of the study, esterification of free fatty acids in the extracted oil could be done with glycerol for production of monoglycerides, diglycerides and triglycerides by using $\mathrm{ZnCl}_{2}$ as a catalyst. Prior to this step, the free fatty acid was determined according to the protocol described in the method part. The free fatty acid was found to be $86.95 \%$ of the extracted oil. Accordingly, it is possible to convert these free fatty acids into glycerides through the esterification process. The experiments were carried out at $195^{\circ} \mathrm{C}, 1: 1$ molar ratio, $0.3 \% \mathrm{ZnCl}_{2}$. The results showed a conversion of $73.4 \%$ of free fatty acids after 30 minutes and $98.5 \%$ of free fatty acids after 


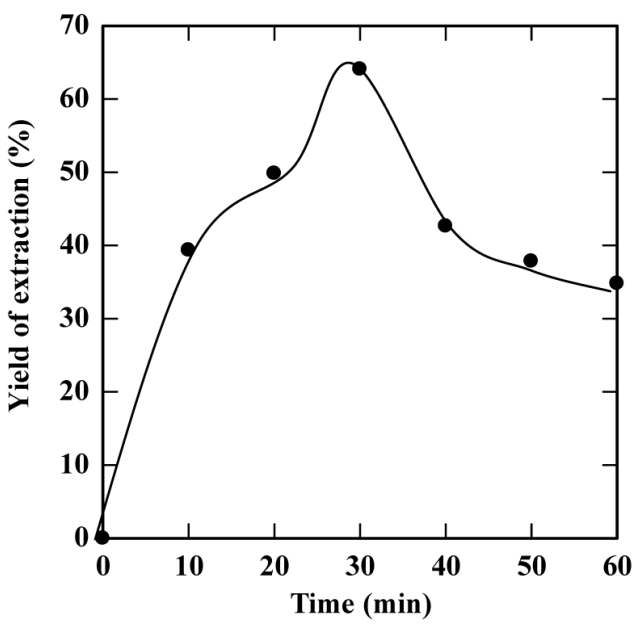

(a)

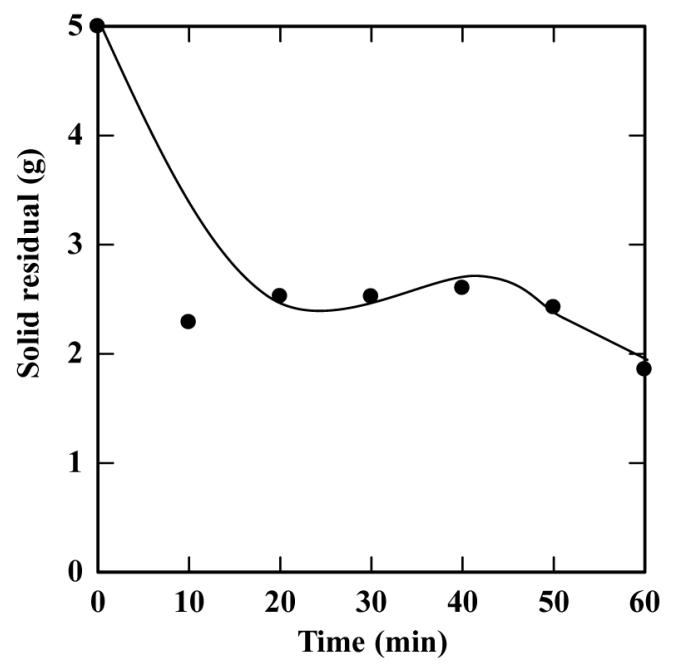

(b)

Figure 5. Effect of extraction time on the yield of extraction (a) and solid residual (b) at $260^{\circ} \mathrm{C}$ The experiments were carried out using feed to solvent ratio of $1: 3$ and extraction time of $30 \mathrm{~min}$.

60 minutes. Figure 8 indicates that the esterification process achieved almost $99 \%$ after 60 minutes.

To prove the esterification process succeeded, samples were taken for both IR and thin layer chromatograph analyses. As shown in Figure 9, the IR analysis showed the existence of the carbonyl group which proved the ester formation. In addition, the thin layer chromatograph analysis (as shown in Figure 10) shows the existence of three main products of mono-, di- and triglycerides.

\subsection{Results of the Kinetic Study}

The kinetic study of the oil extraction from SBE under subcritical water conditions was based on consecutive steps. In these steps, the oil was firstly extracted from inside the powder by diffusion following a first orderlike mechanism. Then the extracted oil, due to extending

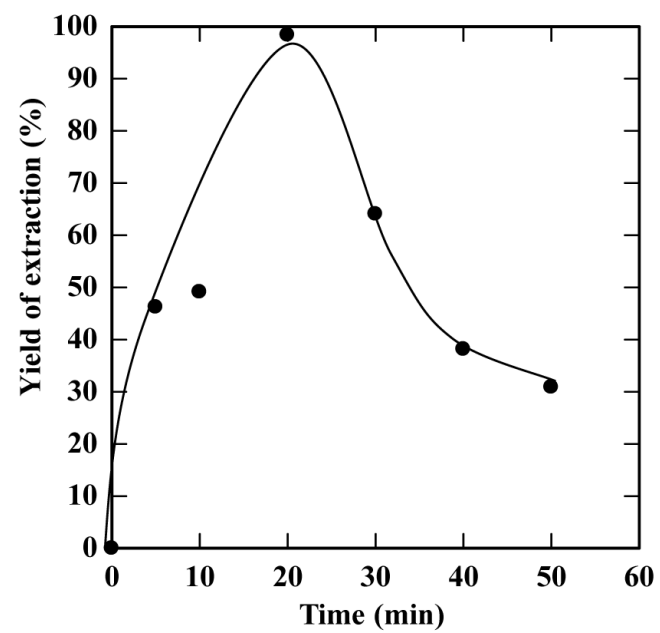

(a)

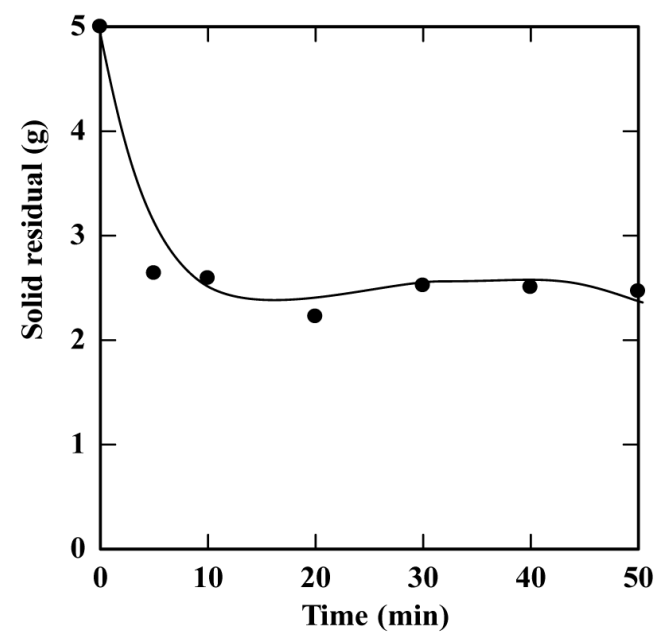

(b)

Figure 6. Effect of extraction time on the yield of extraction (a) and solid residual (b) at $270^{\circ} \mathrm{C}$ The experiments were carried out using feed to solvent ratio of $1: 3$ and extraction time of $30 \mathrm{~min}$.

the extraction time under high temperature and pressure, was subjected to a decomposition reaction following a first order mechanism. Figure 11 shows the results of the time course of the oil extraction under subcritical water in the range of 5 - 60 minutes at different temperatures in the range of $180^{\circ} \mathrm{C}-270^{\circ} \mathrm{C}$.

The experimental data correlated well with the irreversible consecutive unimolecular-type first order mechanism using Equation (6). The values of both oil extraction rate constant and decomposition rate constant were calculated through non-liner fitting using DataFit software. Table 1 shows the obtained values of the rate constants. The extraction rate constants were $0.018,0.03$, $0.08,0.1$ and $0.14 \mathrm{~min}^{-1}$, while the decomposition rate constants were $0.016,0.012,0.02,0.025$ and 0.0205 $\min ^{-1}$ at extraction temperatures of $180^{\circ} \mathrm{C}, 230^{\circ} \mathrm{C}, 250^{\circ} \mathrm{C}$, $260^{\circ} \mathrm{C}$ and $270^{\circ} \mathrm{C}$, respectively. The results showed that 


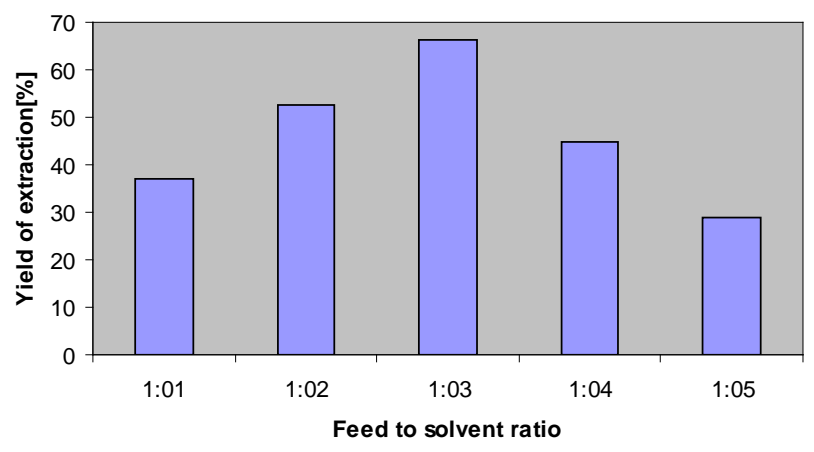

Figure 7. Effect of feed-to-solvent ratio on the yield of extraction The experiments were carried out using extraction time of $30 \mathrm{~min}$ at $270^{\circ} \mathrm{C}$.

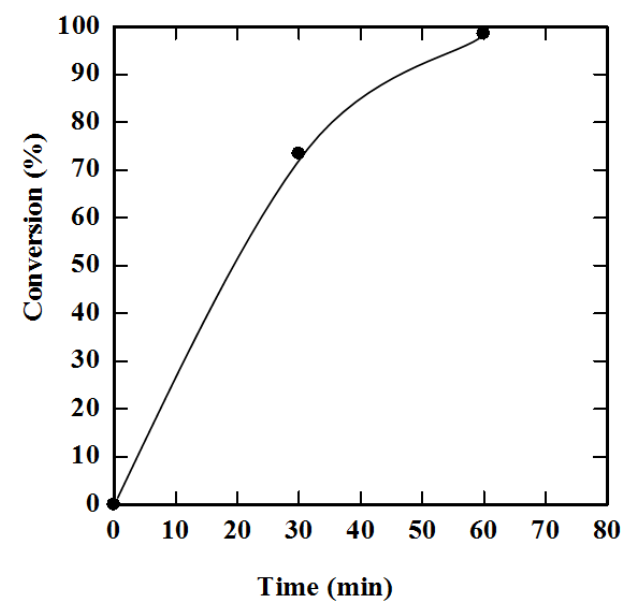

Figure 8. Effect of time on the esterification yield at $195^{\circ} \mathrm{C}$. by increasing the extraction temperature, the extraction rate increases. However, the decomposition rate increased up to a certain value then became almost constant by increasing the extraction temperatures. Table 1 shows the oil extraction and decomposition rate constants at different extraction temperatures.

\subsection{Thermodynamic Parameters}

In this section, the thermodynamic properties of the oil extraction process were investigated. Figure 12 shows the Arrhenius plot for the process. This plot represents the relation between the inverse of the absolute extraction temperature on the $\mathrm{x}$-axis and the extraction rate constant on the $y$-axis. The values of the slope and the intercept were 5549 and 8.034, respectively. The activation energy, E, and the frequency factor, A, were calcu lated from these values using Equation (7). Accordingly, the values of $\mathrm{E}$ and $\mathrm{A}$ were $46.1 \mathrm{~kJ} \cdot \mathrm{mol}^{-1}$ and 3084.05

Table 1. The oil extraction and decomposition rate constants at different extraction temperatures.

\begin{tabular}{ccc}
\hline Temperature $\left({ }^{\circ} \mathrm{C}\right)$ & $\begin{array}{r}\text { Oil Extraction Rate, } \\
\mathrm{k},\left(\mathrm{min}^{-1}\right)\end{array}$ & $\begin{array}{c}\text { Oil Decomposition } \\
\text { Rate, } \mathrm{k},\left(\mathrm{min}^{-1}\right)\end{array}$ \\
\hline 180 & 0.018 & 0.016 \\
230 & 0.03 & 0.012 \\
250 & 0.08 & 0.02 \\
260 & 0.1 & 0.025 \\
270 & 0.14 & 0.0205 \\
\hline
\end{tabular}

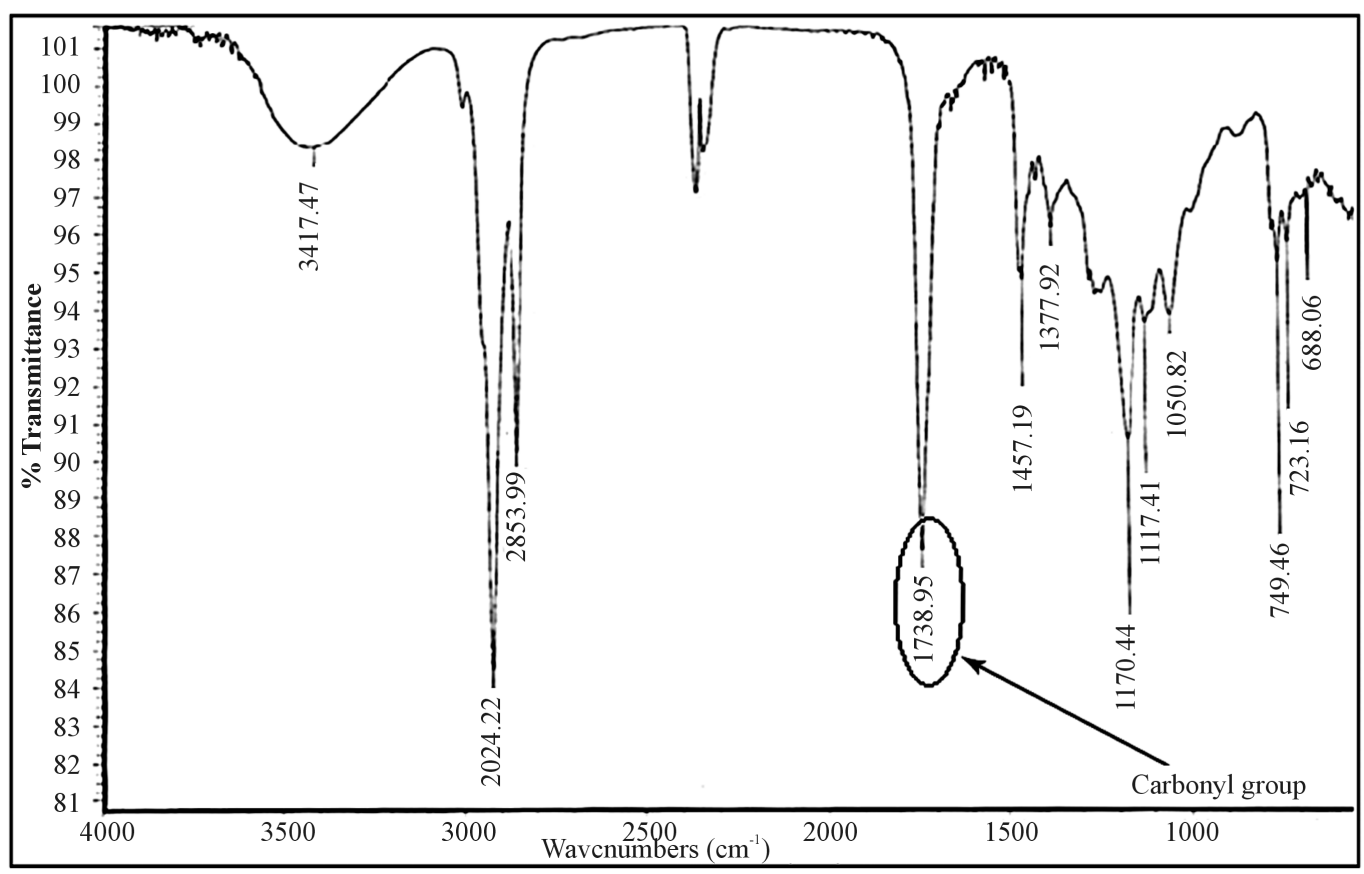

Figure 9. IR analysis of esterificated fatty acids. 


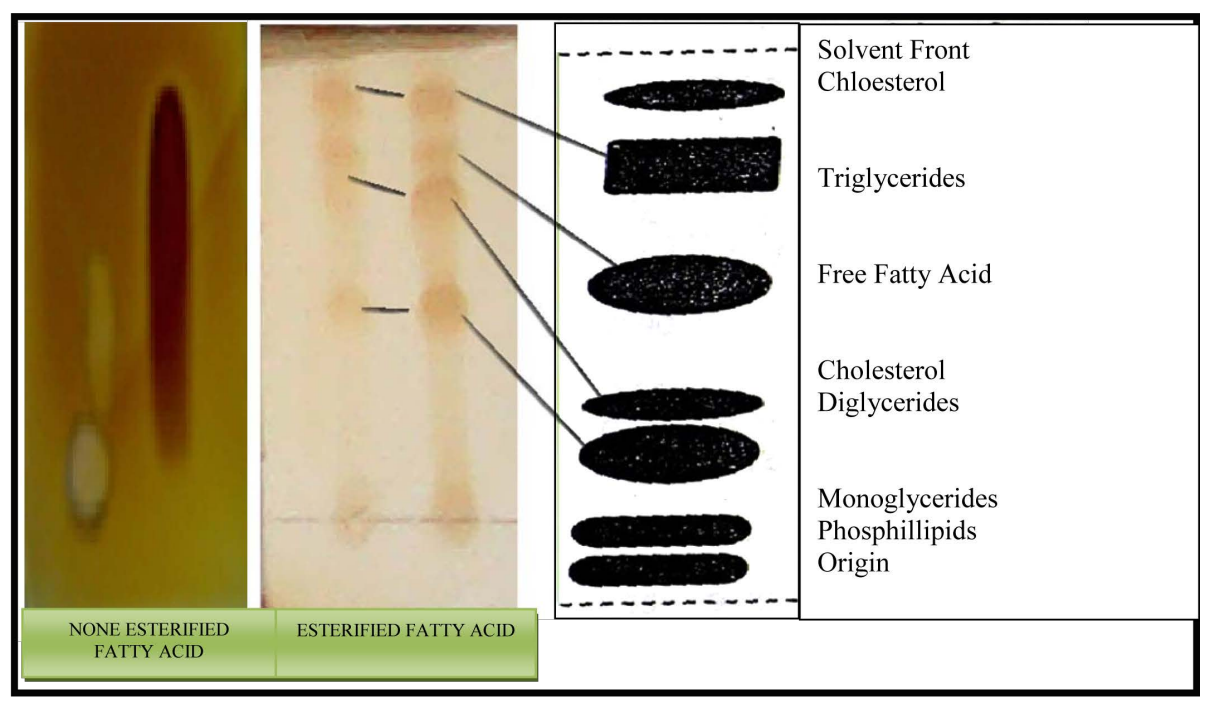

Figure 10. TLC analysis for esterification of unsaturated fatty acids.

$\min ^{-1}$, respectively. Based on these values, let us discuss the mechanism of the extraction process. Generally, energies of activation below $50 \mathrm{~kJ} \cdot \mathrm{mol}^{-1}$ generally indicate diffusion-controlled processes and higher values represent chemical reaction processes [15]. In terms of $E_{\mathrm{a}}$, diffusion-controlled reactions are those governed by mass transfer or diffusion of the aqueous phase from the solid reactant to the bulk solution. Accordingly, the obtained activation energy value indicates clearly a diffusion control mechanism for the oil extraction process.

To gain a deeper understanding of the extraction process, the activation thermodynamic $\Delta H^{\#}$ and $\Delta S^{\#}$ parameters were calculated from the transit-state theory.

Figure 13 shows the Eyring plot for the oil extraction processes. The plot represents the relationship between the inverse of the absolute extraction temperature on the $\mathrm{x}$-axis and the $\ln (\mathrm{k} / \mathrm{T})$ on the $\mathrm{y}$-axis. The values of the slope and the intercept were -5056 and 0.84 , respectively. From these values the standard enthalpy of activation $\left(\Delta \mathrm{H}^{\#}\right)$ and the standard entropy of activation $\left(\Delta \mathrm{S}^{\#}\right)$ were calculated using Equation (11). The value of $\Delta \mathrm{H}^{\#}$ was $-42.038 \mathrm{~kJ} \cdot \mathrm{mol}^{-1}$ and the value of $\Delta \mathrm{S}^{\#}$ was -0.1906 $\mathrm{kJ} \cdot \mathrm{K}^{-1} \cdot \mathrm{mol}^{-1}$. The value of $\Delta \mathrm{S}^{\#}$ gives information about the degree of order in the transition state. Low values of $\ln$ A correspond to large negative values of $\Delta \mathrm{S}^{\#}$, indicating unfavorable reactions, which means that the activated complex in the transition state has a more ordered or more rigid structure than the reactants in the ground state. This is generally the case if degrees of freedom (of translation, rotation, vibration) become "frozen" on the route from the initial to the transition state. The reaction rate is then slow in this case. On the other hand, high values of $\ln A$ correspond to positive values of $\Delta S^{\#}$, indicating favorable reactions. A positive value for entropy of activation indicates that the transition state is highly disordered compared to the ground state. Translational, rotational and vibrational degrees of freedom are liberated on going from the ground state to the transition state and then the reaction proceeds fast (Abdelmoez et al., 2012).

In this case, the value obtained for $\Delta S^{\#}$ was found to be negative. These results indicate that the transition state was more ordered than the ground one in the oil extraction process.

The values of the Gibbs free energy of activation were calculated at different temperatures using Equation (12). Table 2 shows a summary of the thermodynamic extraction parameters derived from the Arrhenius and Eyring equations for the extraction process.

The obtained values for $\Delta \mathrm{G}^{\#}$ were 44.3, 53.8, 57.6, 59.5 and $61.4 \mathrm{~kJ} \cdot \mathrm{mol}^{-1}$ at $180^{\circ} \mathrm{C}, 230^{\circ} \mathrm{C}, 250^{\circ} \mathrm{C}, 260^{\circ} \mathrm{C}$ and $270^{\circ} \mathrm{C}$, respectively. The positive values indicate a non-spontaneous reaction while the negative value indicates a spontaneous process. These results explained why high extraction temperatures and pressure are needed for improving the extraction process to overcome the nonspontaneous nature of the process.

\section{CONCLUSION}

In this work, subcritical water has been used as a new pathway for oil extraction from spent bleaching earth. The main conclusions from this work are that the optimum oil extraction temperature is $270^{\circ} \mathrm{C}$, the optimum extraction time is 20 minutes, and the optimum feed: solvent ratio is $1: 3$. Free fatty acids from waste oil extracted can be esterified to mono-, di- and triglycerides in an esterification reaction. Therefore, the esterification of waste oil will provide two major benefits: firstly, it will make the production of biodiesel more competitive with the existing diesel fuel market, and secondly, it will pro- 


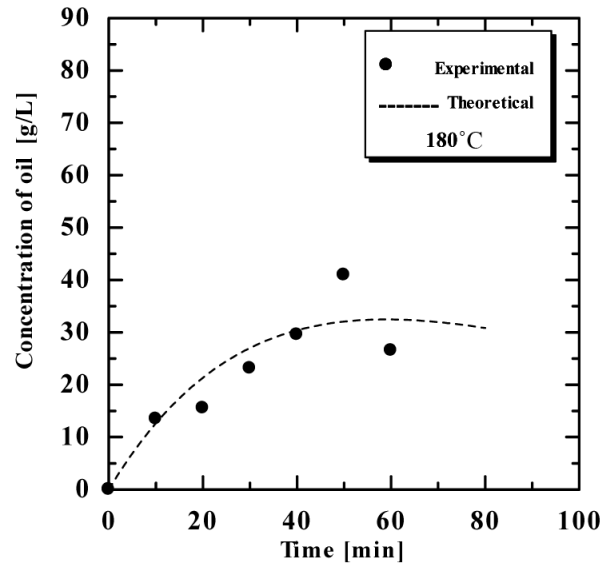

$C_{0 i \mathrm{i}}=83.3 * k_{1} *\left[\left(\left(\operatorname{Exp}\left(-k_{1} * t\right)\right) /\left(k_{2}-k_{1}\right)\right)+\left(\left(\operatorname{Exp}\left(-k_{2} * t\right)\right) /\left(k_{1}-k_{2}\right)\right)\right]$

$$
\begin{aligned}
\mathbf{k} 1 & =0.018 \\
\mathbf{k} & =0.016 \\
|\mathbf{r}| & =\mathbf{0 . 9 1 8}
\end{aligned}
$$

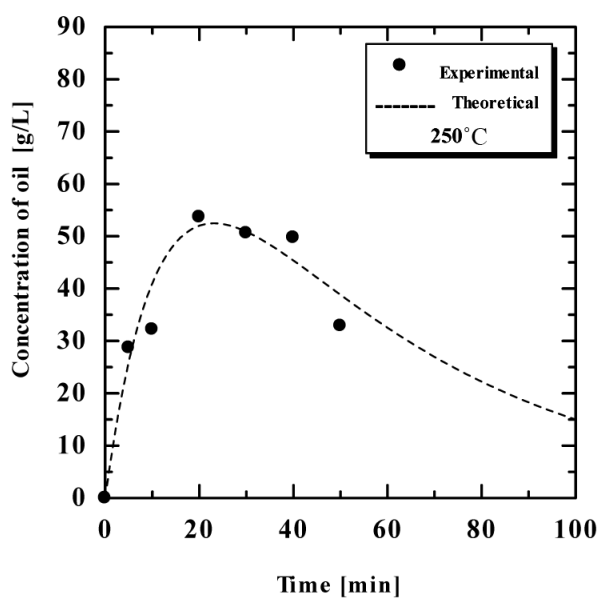

$\mathrm{C}_{\text {oi }}=83.3 * \mathrm{k}_{1} *\left[\left(\left(\operatorname{Exp}\left(-\mathrm{k}_{1} * t\right)\right) /\left(\mathrm{k}_{2}-\mathrm{k}_{1}\right)\right)+\left(\left(\operatorname{Exp}\left(-\mathrm{k}_{2} * t\right)\right) /\left(\mathrm{k}_{1}-\mathrm{k}_{2}\right)\right)\right]$

$$
\begin{aligned}
& \mathbf{k}=\mathbf{0 . 0 8} \\
& \mathbf{k}=\mathbf{0 . 0 2} \\
& |\mathbf{r}|=\mathbf{0 . 9 6 7}
\end{aligned}
$$

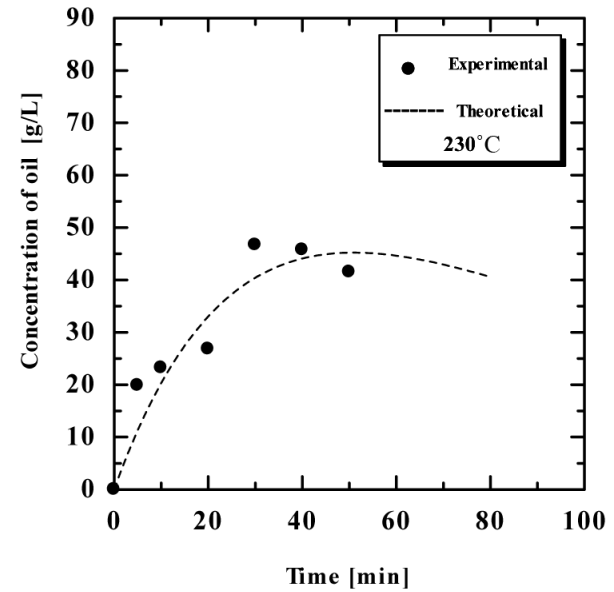

$C_{\text {oif }}=83.3 * k_{1} *\left[\left(\left(\operatorname{Exp}\left(-k_{1} * t\right)\right) /\left(k_{2}-k_{1}\right)\right)+\left(\left(\operatorname{Exp}\left(-k_{2} * t\right)\right) /\left(k_{1}-k_{2}\right)\right)\right]$ $\mathbf{k} 1=0.03$
$\mathbf{2}=\mathbf{0 . 0 1 2}$ $12=0.012$
$|\mathbf{r}|=0.956$

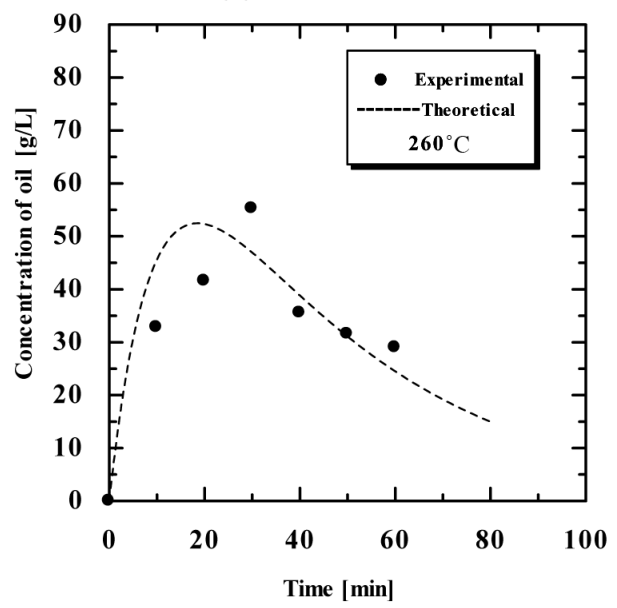

$C_{\text {oil }}=75 * k_{1} *\left[\left(\left(\operatorname{Exp}\left(-k_{1} * t\right)\right) /\left(k_{2}-k_{1}\right)\right)+\left(\left(\operatorname{Exp}\left(-k_{2} * t\right)\right) /\left(k_{1}-k_{2}\right)\right)\right]$

$\mathbf{k 1}=\mathbf{0 . 1}$

k2=0.0.025

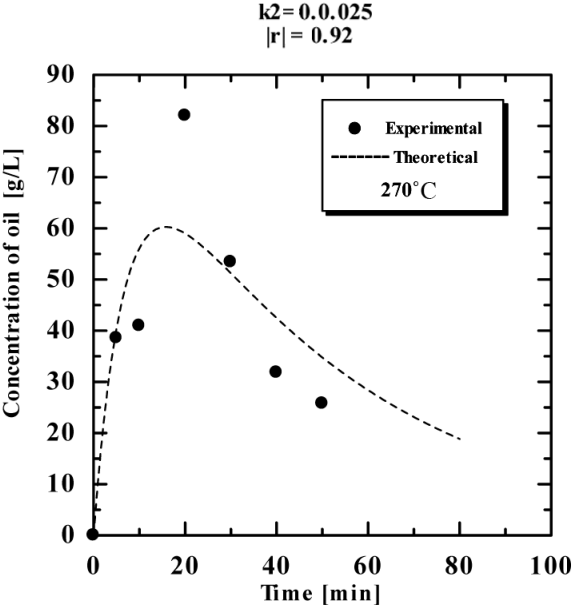

$C_{o i i}=75^{*} k_{1} *\left[\left(\left(\operatorname{Exp}\left(-k_{1} * t\right)\right) /\left(k_{2}-k_{1}\right)\right)+\left(\left(\operatorname{Exp}\left(-k_{2} * t\right)\right) /\left(k_{1}-k_{2}\right)\right)\right]$

$$
\begin{aligned}
& \mathbf{k} 1=0.14 \\
& \mathbf{k} 2=\mathbf{0 . 0 2 0 5} \\
& |\mathbf{r}|=\mathbf{0 . 8 4 4}
\end{aligned}
$$

Figure 11. the time course of the extraction of oil from SBE at different temperature, experimental data compared to theoretical obtained data. 


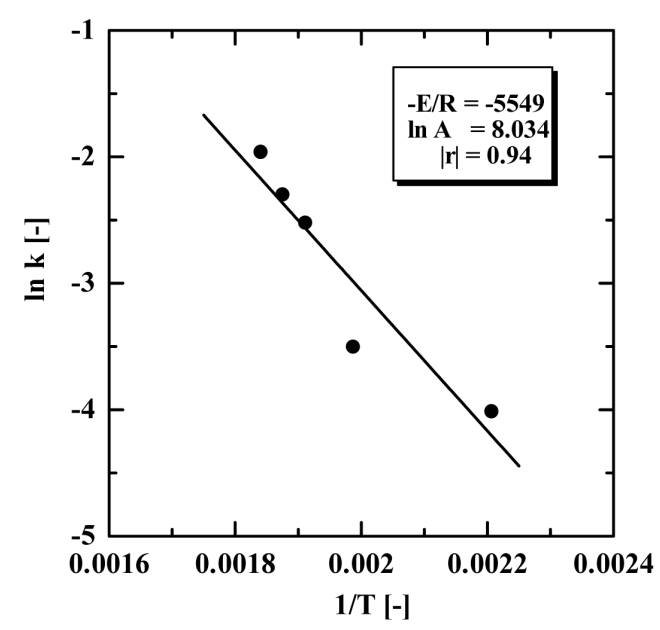

Figure 12. The Arrhenius plot of oil extraction process in the range of $180^{\circ} \mathrm{C}-270^{\circ} \mathrm{C}$.

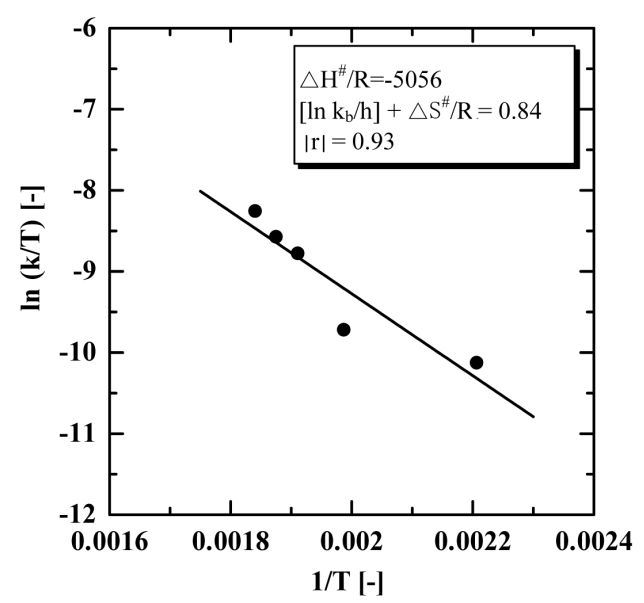

Figure 13. The Eyring plot of oil extraction process in the range of $180^{\circ} \mathrm{C}-270^{\circ} \mathrm{C}$.

Table 2. A summary of the extraction parameters derived from the Arrhenius and Eyring equations for the extraction process.

\begin{tabular}{cc}
\hline Temperature $\left({ }^{\circ} \mathbf{C}\right)$ & $\Delta \mathbf{G}^{\#}\left(\mathbf{k J} \cdot \mathbf{m o l}^{-\mathbf{1}}\right)$ \\
\hline 180 & 44.3 \\
230 & 53.8 \\
250 & 57.6 \\
260 & 59.5 \\
270 & 61.4 \\
\hline
\end{tabular}

duce monoglycerides and diglycerides, the most important emulsifiers used in the food industry.

\section{REFERENCES}

[1] Pollard, S.J.T. (1990) Low-cost adsorbents from industrial wastes. Ph.D. Thesis, Imperial College, London.
[2] Environment Agency (EA) Guidance (2006) Guidance for waste destined for disposals in landfills, version 2, Interpretation of the waste acceptance requirements of the landfill (England and Wales) Regulations (as amended). http://www.environment-agency.gov.uk/

[3] Ramadan, A.R., Kock, P. and Nadim, A. (2005) Nasreya: A treatment and disposal facility for industrial hazardous waste in Alexandria, Egypt: Phase I. Waste Management and Research, 23, 167-170. http://dx.doi.org/10.1177/0734242X05053689

[4] Al-Zahrani, A.A. and Daous, M.A. (2000) Recycling of spent bleaching clay and oil recovery. Institution of Chemical Engineers Transactions, 78, 224-228.

[5] Chang, J.I., Tai, H.-S. and Huang T.-H. (2006) Regeneration of spent bleaching earth by lye-extraction. Environmental Progress, 25, 373-378.

[6] Park, E.Y., Sato, M. and Kojima, S. (2008) Lipase-catalyzed biodiesel production from waste activated bleaching earth as raw material in a pilot plant. Bioresource Technology, 99, 3130-3135. http://dx.doi.org/10.1016/j.biortech.2007.05.059

[7] Pizarro, A.V.L. and Park, E.Y. (2003) Lipase-catalyzed production of biodiesel fuel from vegetable oils contained in waste activated bleaching earth. Process Biochemistry, 38, 1077-1082. http://dx.doi.org/10.1016/S0032-9592(02)00241-8

[8] Loh, S.K., Cheng, S.F., Choo, Y.M. and Ma, A.N. (2006) A study of residual oils recovered from spent bleaching earth: Their characteristics and applications. American Journal of Applied Sciences, 3, 2063-2067. http://dx.doi.org/10.3844/ajassp.2006.2063.2075

[9] Kiran, E., Debenedetti, P.G. and Peter, C.J. (2000) Supercitical fluids, fundamentals and applications. Kluwer Academic Publishers, Dordrecht, 425-437.

[10] Modell, M. (2001) SCWO Historical perspective supercritical water oxidation-Achievements and Challenges in Commercial Applications Strategic Analysis, Inc.

[11] Yoshida, H., Terashima, M. and Takahashi, Y. (1999) Production of organic acids and amino acids from fish meat by subcritical water hydrolysis. Biotechnology Progress, 15, 1090-1094. http://dx.doi.org/10.1021/bp9900920

[12] Abdelmoez, W. and Yoshida, H. (2006) Synthesis of a novel protein-based biodegradable plastic from the BSA using the sub-critical water technology. AIChE Journal, 52, 2607-2616. http://dx.doi.org/10.1002/aic.10849

[13] Abdelmoez, W. and Yoshida, H. (2008) Kinetics and mechanism of the synthesis of novel protein-based plastic using subcritical water. Biotechnology Progress, 24, 466475.

[14] Abdelmoez, W., Abdelfatah, R., Tayeb, A. and Yoshida, H. (2011) Extraction of cottonseed oil using subcritical water technology. AIChE Journal, 57, 2353-2359. http://dx.doi.org/10.1002/aic.12454

[15] Abdelmoez, W., Abdelhamid, M. and Yoshida, H. (2012) Extraction of jojoba oil using subcritical water technology. Recent Patents on Chemical Engineering, 5, 63-70.

[16] Abdelmoez, W., Yoshida, H. and Nakahasi, T. (2010) 
Pathways of amino acid transformation and decomposition in saturated subcritical water conditions. International Journal of Chemical Reactor Engineering, 8, A107.

[17] Abdelmoez, W. and Yoshida, H. (2013) Production of amino and organic acids from proteins using sub-critical water technology. International Journal of Chemical Re- actor Engineering, 11, 1-16.

[18] Mostafa, N., Maher, A. and Abdelmoez, W. (2013) Production of mono-, di-, and triglycerides from waste fatty acids through esterification with glycerol. Advances in Bioscience and Biotechnology, 4, 900-907. http://dx.doi.org/10.4236/abb.2013.49118 